Published in final edited form as:

Nature. ; 487(7406): 196-201. doi:10.1038/nature11181.

\title{
Watching DNA polymerase $\eta$ make a phosphodiester bond
}

\author{
Teruya Nakamura ${ }^{1,2,4}$, Ye Zhao ${ }^{1,3,4}$, Yuriko Yamagata ${ }^{2}$, Yue-jin Hua ${ }^{3}$, and Wei Yang ${ }^{1}$ \\ ${ }^{1}$ Laboratory of Molecular Biology, NIDDK, NIH, Bethesda, MD 20892, USA \\ ${ }^{2}$ Graduate School of Pharmaceutical Sciences, Kumamoto University, Kumamoto 862- 0973, \\ Japan \\ ${ }^{3}$ Institute of Nuclear-Agricultural Sciences, Zhejiang University, Hangzhou 310029, China
}

\begin{abstract}
Native human DNA polymerase $\eta$, DNA and dATP were crystallized at $\mathrm{pH} 6.0$ without $\mathrm{Mg}^{2+}$. The polymerization reaction was initiated by exposing crystals to $1 \mathrm{mM} \mathrm{Mg}^{2+}$ at $\mathrm{pH} 7.0$, and stopped at various time points by freezing at $77 \mathrm{~K}$ for crystallographic analysis. The substrates and two $\mathrm{Mg}^{2+}$ are aligned for reaction within 40 seconds, but the new bond begins to form at 80 seconds. Structures at reaction times from 80 s to 300 s reveal a mixture of decreasing substrate and increasing product of the nucleotidyl-transfer reaction. In sequence, the nucleophile $3^{\prime}-\mathrm{OH}$ is deprotonated, the deoxyribose at the primer end converts from $\mathrm{C} 2^{\prime}$-endo to $\mathrm{C} 3^{\prime}$-endo to avoid steric clashes, and the nucleophile and the a-phosphate of dATP approach each other to form the new bond. A third $\mathrm{Mg}^{2+}$ ion, which arrives with the new bond and stabilizes the intermediate state, may be an unappreciated feature of the two-metal-ion mechanism.
\end{abstract}

\section{Keywords}

nucleotidyl transfer; DNA polymerase; $\mathrm{Mg}^{2+}$; deprotonation; sugar pucker

Formation and breakage of chemical bonds underlie all life processes. DNA replication, which is essential for cell proliferation, is but one example ${ }^{1,2}$. In each reaction cycle, a dNTP complementary to the templating base is incorporated into DNA in a nucleotidyltransfer reaction catalyzed by a polymerase, during which a new bond is formed between the $3^{\prime}-\mathrm{OH}$ of the primer strand and the a-phosphate of the dNTP and the phosphodiester bond between $\alpha$ and $\beta$-phosphates of dNTP is broken (Fig. 1a). As a result the primer strand is extended by one nucleotide and a pyrophosphate is released. This reaction has been shown

\footnotetext{
Users may view, print, copy, download and text and data- mine the content in such documents, for the purposes of academic research, subject always to the full Conditions of use: http://www.nature.com/authors/editorial_policies/license.html\#terms

Correspondence and requests for materials should be addressed to W.Y. (wei.yang@nih.gov).

4 These authors contributed equally.

Author contributions

T.N. and Y.Z. carried out crystallography. Y.Z. did mutagenesis and kinetic analyses. T.N. handled crystals, refined structures and analyzed reaction time courses. W.Y. designed the project. T.N., Y.Z. and W.Y. prepared the manuscript. T.N. and Y.Z. contributed equally to the study. Y.Y. supervised T.N. and Y.H. advised Y.Z.. All authors discussed the results and commented on the manuscript

Atomic coordinates and structure factors for the reported crystal structures have been deposited with the Protein Data Bank with accession codes from 4ECQ to 4ECZ, 4ED0 to 4ED3, and 4ED6 to 4ED8

The authors declare no competing financial interests.
} 
to require two $\mathrm{Mg}^{2+}$ ions and inferred to be the associative $\mathrm{S}_{\mathrm{N}} 2$ type with a pentacovalent phosphate intermediate ${ }^{3}$. A similar two-metal-ion dependent mechanism is believed to be shared by all DNA and RNA polymerases and many nucleases ${ }^{4,5}$.

DNA synthesis has been analyzed by kinetic measurements, dynamic simulations, and structural studies ${ }^{2,6,7}$. Crystal structures of a number of DNA polymerases in substratebound forms have been determined using non-reactive substrate analogs or $\mathrm{Ca}^{2+}$ instead of $\mathrm{Mg}^{2+}$ to prevent the nucleotidyl transfer reaction ${ }^{5,8-18}$. These structures reveal active-site configurations in an array of pre-reaction ground states. Exquisite pre-steady state kinetic studies of several DNA polymerases indicate that after large conformational changes induced by substrate binding, unspecified subtle conformational changes in the active site are the rate-limiting step ${ }^{19-27}$. The actual process of DNA synthesis has never been visualized.

Human DNA polymerase $\eta(\mathrm{hPol} \eta)$ is specialized in lesion bypass and has a preformed catalytic center that undergoes limited conformational change during DNA synthesis ${ }^{28}$. Crystal structures of the catalytic domain of hPol $\eta$ complexed with DNA and a non-reactive dNTP analog poised for catalysis have been determined at 1.8 A resolution ${ }^{29,30}$. Taking advantage of the slow reaction rate and hindered post-reaction DNA translocation in crystallo, we follow the course of DNA synthesis by X-ray crystallography and report here structural changes and transient elements that are associated with the reaction.

\section{The Ground State of hPol $\eta$}

The $\mathrm{hPol} \eta$ activity in a reaction buffer containing $0.9 \mathrm{mM} \mathrm{Mg}^{2+}$ and $0.1 \mathrm{mM} \mathrm{Ca}^{2+}$ was only one-thirds of that with $1 \mathrm{mM} \mathrm{Mg}^{2+}$ (Fig. 1b), suggesting that both active-site metal ions have to be $\mathrm{Mg}^{2+}$ for the catalysis. In accordance with the bell-shaped $\mathrm{pH}$-dependence curve characteristic for the acid-base catalysis ${ }^{17,31}$, the catalytic rate of hPol $\eta$ is extremely low at pH 6.0 and rises with increasing $\mathrm{pH}$ from 6.0 to 8.0 (Fig. 1c). To prevent nucleotidyltransfer reaction, crystals of native $\mathrm{hPol} \eta$-substrate complexes were grown at $\mathrm{pH} 6.0$ with only one $\mathrm{Ca}^{2+}$ per protein-DNA-dATP complex (Methods). After soaking in MES (pH 6.07.2) or HEPES buffer ( $\mathrm{pH} 7.0-7.5$ ) with $\mathrm{Na}^{+}$or $\mathrm{K}^{+}$but no divalent cation for 5 to $30 \mathrm{~min}$, these crystals maintained excellent diffraction up to $\mathrm{pH} 7.0$, but decayed at $\mathrm{pH} 7.5$ with reduced resolution and increased diffuse scattering.

The structure of hPol $\eta$ crystal equilibrated at $\mathrm{pH} 6.8$ was refined at $1.50 \AA . \mathrm{A} \mathrm{Ca}^{2+}$ ion clearly occupies the $\mathrm{B}$ metal-ion binding site and is coordinated in the octahedral geometry by oxygen atoms of the dATP and the active-site residues (Fig. 1d). The A site has low occupancy of a monovalent cation. The occupancy of $\mathrm{Na}^{+}$or $\mathrm{K}^{+}$in the A-site increases with the $\mathrm{pH}$ (Supplementary Fig. 1a,b), which is probably correlated with deprotonation of the active-site carboxylates. $\mathrm{hPol} \eta$ binds $\mathrm{Na}^{+}$more readily than $\mathrm{K}^{+}$, particularly below $\mathrm{pH}$ 7.0, probably because $\mathrm{Na}^{+}$is similar to $\mathrm{Mg}^{2+}$ in size and smaller than $\mathrm{K}^{+}$. As expected, there is no nucleotidyl-transfer reaction, and the structure is termed the ground-state ternary complex (GS).

The GS structure is overall similar to the hPol $\eta$ ternary complex with a non-reactive dATPanalog (dAMPNPP) and two $\mathrm{Mg}^{2+}$ ions (PDB 3MR2) ${ }^{29}$. However, without an A-site 
divalent cation, the $3^{\prime}-\mathrm{OH}$ of the primer strand shifts away from the dATP and forms hydrogen bonds with the sidechains of S113 and D115, and the active-site carboxylates D13 and E116 adopt different rotamer conformations (Fig. 1d). Replacement of dAMPNPP with dATP leads to stabilization of R61, which makes bidentate hydrogen bonds with the aphosphate.

\section{Catalysis in crystallo}

The nucleotidyl transfer was initiated by transferring hPol $\eta$ crystals to a $\mathrm{pH} 6.8$ or 7.0 reaction buffer containing $1 \mathrm{mM} \mathrm{Mg}^{2+}$ but no dATP (Methods). After incubation at $293 \mathrm{~K}$ for 40 s to 300 s, the reaction was terminated in $\sim 40$ s intervals by freezing crystals in liquid nitrogen at $77 \mathrm{~K}$. Diffraction data were collected to $1.50-1.95 \AA$ Aragg spacings (Supplementary Table 1). The reaction process is monitored by the electron density corresponding to the new chemical bond in the Fo-Fc map compared with the refined GS structure (Supplementary Fig. 2, Fig. 2a). The reaction time courses at pH 6.8 and $7.0 \mathrm{in}$ crystallo (Fig. 2b) are $20-100$ fold slower than in solution (Fig. 1c), probably due to the reduced thermal motion. By 40s, the A-site was fully occupied with $\mathrm{Mg}^{2+}$ (Fig. 2a, Supplementary Fig. 1c,d). About $50 \%$ of $\mathrm{Ca}^{2+}$ in the B site was replaced by $\mathrm{Mg}^{2+}$, and exchange of the remaining $\mathrm{Ca}^{2+}$ took place slowly (Supplementary Fig. 3). Binding of two $\mathrm{Mg}^{2+}$ ions leads to the alignment of the $3^{\prime}-\mathrm{OH}$ and dATP ${ }^{18,32}$. The refined structure is nearly identical to that with dAMPNPP (PDB: 3MR2) except for tighter dATP coordination by R61 and closer of the $\mathrm{Mg}^{2+}$ ions (3.4 $\AA$ apart versus $3.6 \AA$ ). Since there is no sign of bond formation, the structure is termed the reactant state (RS).

Electron density corresponding to a new bond between the $3^{\prime}-\mathrm{OH}$ and the a-phosphorus of dATP begins to emerge at 80 seconds, increases quickly in the following $60 \mathrm{~s}$, and reaches its maximum after 200s when the reaction is $60-70 \%$ complete (Fig. 2b). The seemingly reduced rate after 140s is likely due to the reverse reaction in crystallo. The slight decline of product after 250s (Fig. 2b) is due to a sideway product translocation, which is clear with longer incubation (Supplementary Fig 4a). To alleviate an impediment to proper DNA translocation by the crystal lattice, we replaced an AT basepair with a mismatch at the DNA end that formed lattice contacts (Methods, Supplementary Table 2). One DNA with a TG mismatch led to isomorphous crystals and proper translocation of the DNA product (Supplementary Fig 4b). Interestingly, the time courses of nucleotidyl transfer in the AT and TG crystals are nearly identical and unaffected by the lattice contacts (Fig. 2b).

At the peak of chemical bond formation between 200 and 250s, the scissile phosphate can be refined in a penta-covalent transition state without restraints (Fig. 2c). But the bond distances between the phosphorus and the attacking or leaving oxygen atoms are 2.2 to 2.5 $\AA$ (Fig. 2c), much longer than the expected $2.0 \AA$ observed with transition-state mimics like $\mathrm{AlF}_{4}$ or $\mathrm{MgF}_{3}{ }^{33-35}$. Moreover, in the Fo-Fc map residual electron densities are observed around the new and scissile phosphodiester bonds (Fig. 2c). The same diffraction data, however, can be well fitted as a mixture of the reactant (RS) and the product state (PS) immediately before and after the nucleotidyl transfer (Fig 2d). Because the transition state is transient and unstable, the structures obtained between $80 \mathrm{~s}$ and 300s are refined as a mixture 
of the RS and PS at different ratios (Fig. 2b, Supplementary Table 1a). For instance the 1.52 $\AA$ A structure at 230 s contains $40 \%$ substrate and $60 \%$ product complexes.

Between the RS and PS, the protein, DNA and dATP are superimposable except for atoms in the reaction center. Most notably, the a-phosphorus of the dATP moves $1.4 \AA$ along a straight line between the attacking and leaving oxygen atoms (separated by $4.6 \AA$ ) (Fig. 2d). The shift of the a-phosphate is accompanied by alteration of R61 of hPoln, which flips away from the scissile phosphate and is replaced by a new metal ion and water molecules (Fig. $2 \mathrm{a}, \mathrm{d}$, see details below). On the primer strand, changes are confined to the $3^{\prime}$ nucleotide. The $3^{\prime}$-OH together with the deoxyribose moves towards the a-phosphate by $0.5 \AA$, and the sugar pucker changes from $\mathrm{C} 2^{\prime}$ endo in the RS to $\mathrm{C} 3^{\prime}$ endo in the PS (Fig. 2d). With the loss of the nucleophile and a-phosphate as ligands, the A-site $\mathrm{Mg}^{2+}$ dissociates in the PS as evidenced by the declining occupancy (Supplementary Fig 1c,d). Concomitantly, D13 assumes a second conformation and forms an H-bond with K224.

The $\mathrm{C}^{\prime}$-endo (A-form) conformation at the $3^{\prime}$ primer end was observed in ternary complexes with the A, B and X-family DNA polymerases and thought to be important for forming a shallow minor-groove for dNTP selection 9,11,12,14,15,17,18,32. Among the Yfamily polymerases, the primer end has always been observed as $\mathrm{C}^{\prime}$-endo ${ }^{28}$. In the $\mathrm{hPol} \eta$ GS and RS complexes, the dATP and the nucleotide $5^{\prime}$ to the primer end have the A-form conformation, but only in the PS structure does the primer end adopt the $\mathrm{C}^{\prime}$-endo conformation to avoid clashes between its $\mathrm{C} 2^{\prime}$ atom and the non-bridging oxygen of dATP during and immediately after the nucleophilic attack (Fig. 2d, 3a). Since the electron density is weak for the sugar moiety at the $3^{\prime}$-primer end, we tested the effect of the A-form conformation by using a primer with a ribonucleotide at its $3^{\prime}$ end. The catalytic efficiency $\left(\mathrm{k}_{\mathrm{cat}} / \mathrm{K}_{\mathrm{M}}\right.$ ) of hPol nis comparable whether it is rA- or dA (Fig. 3b), as observed for DNA pol $\beta^{36}$, indicating that the A-form conformation is probably necessary for DNA synthesis in general.

\section{A Transient Water Molecule}

Two unexpected spheres of electron density appear in the Fo-Fc maps in the course of new bond formation (Fig. 2a). The first is within hydrogen bonding distance of the $3^{\prime}-\mathrm{OH}$. Its electron density peaks at 80 s and drastically declines after 140s when the PS becomes prominent. Although absent in the GS and the 40s RS structure, the electron density is superimposable with a water molecule observed in the hPol $\eta$-dAMPNPP ternary complex (3MR2). This water is hydrogen bonded with the $3^{\prime}-\mathrm{OH}$, the $\mathrm{O}^{\prime}$ of dATP and another water in the 80s RS structure, but it is incompatible with the $\mathrm{C}^{\prime}$-endo conformation in the PS (Fig. 3a). The $3^{\prime}-\mathrm{OH}$ is also hydrogen bonded to a water molecule in an X-family DNA polymerase crystallized with dUMPNPP ${ }^{32}$. A water-mediated and substrate-assisted catalytic mechanism was proposed previously ${ }^{37,38}$. Besides this water, S113 is hydrogen bonded with the $3^{\prime}-\mathrm{OH}$ in the GS and may pick up the proton and passes it to E116 in the RS (Fig. 1d). However, the S113A mutant hPol $\eta$ retains $95 \%$ of $k_{\text {cat }}$ with a 3-fold increase of $\mathrm{K}_{\mathrm{M}}$ (Fig. 3b, Supplementary Table 3). Interestingly, mutations of the S113-equivalent in the A- and B-family DNA polymerases (highly conserved histidine and threonine, respectively) have limited impact on catalytic efficiency ${ }^{39-41}$. We therefore propose that $3^{\prime}-\mathrm{OH}$ is prone 
to deprotonation when coordinated by the $\mathrm{Mg}^{2+}$ and aligned with the incoming nucleotide ${ }^{4}$. The proton can be passed onto the transient water molecule and then to bulk solvent. When the $3^{\prime}$-end of primer is a ribonucleotide, the $\mathrm{O} 2^{\prime}$ may relay the proton out instead. An incoming dNTP most probably participates in deprotonation of the nucleophile because with the nitrogen substitution in dAMPNPP the water molecule is stably bound to the $3^{\prime}$ $\mathrm{OH}^{29,30}$.

\section{The Third Metal Ion}

The second emerging sphere of electron density is very close to the a-phosphate on the opposite side of the A- and B-site $\mathrm{Mg}^{2+}$ ions (Fig. 2a). It starts to appear at 140s and intensifies with the reaction time. By 230 s with the structure refined at $1.52 \AA$ resolution, the octahedral geometry and the short coordination distances indicate that this is a divalent cation and most likely $\mathrm{Mg}^{2+}$ (Fig. 4). This third metal ion is liganded by four water molecules, two of which occupy the space of the departed R61 (Fig. 2d). Two additional ligands are the leaving oxygen (bridging between the $\alpha$ and $\beta$ phosphate) and the nonbridging oxygen of the a-phosphate (Fig. 4). This $\mathrm{Mg}^{2+}$ thus bridges the two reaction products destined to separate and prevents DNA translocation. In the TG crystals with $1 \mathrm{mM}$ $\mathrm{Mg}^{2+}$ in the reaction buffer, the mixed RS and PS intermediate stays at equilibrium for up to 15 minutes, but with reduced $\mathrm{Mg}^{2+}(5 \mu \mathrm{M})$ and addition of dATP $(5 \mu \mathrm{M})$, product release occurs much faster (Supplemental Information). The physiological role of the third metal ion is likely to neutralize the negative charge built up in the transition state and may also facilitate protonation of the pyrophosphate.

Three metal ions have been structurally observed in a number of enzymes catalyzing phosphoryl-transfer reactions, including alkaline phosphatase, P1 nuclease and Endo IV $33,42-44$. In the case of Endo IV, the three $\mathrm{Zn}^{2+}$ ions observed in both substrate and product state ${ }^{44}$ are reminiscent of the $\mathrm{Mg}^{2+}$ with hPol $\eta$ (Supplementary Fig. 5). The two metal ions essential for catalysis flank the scissile phosphate on one side, and the third metal ion bridges the reaction products on the other. A similar arrangement of three metal ions was proposed for group I introns based on chemical probing ${ }^{45}$. However, the third metal ion was absent in crystal structure of a splicing intermediate, likely due to its transient nature ${ }^{46}$.

\section{Concluding Remarks}

Previously, flash-freeze was used to trap covalent intermediates and conformational changes associated with a chemical reaction ${ }^{47-49}$. Here we extend the technology to record DNA synthesis in real time and at atomic resolution (Fig. 5, Supplementary Movie 1). The arrival of a water molecule to deprotonate the $3^{\prime}-\mathrm{OH}$ occurs only after two- $\mathrm{Mg}^{2+}$ induced substrate alignment and in the presence of a correct dNTP but not a non-reactive dAMPNPP. $\mathrm{Mg}^{2+}$ dependent and water-mediated deprotonation may occur in all DNA polymerases. The third metal ion that replaces the sidechain of R61 during the nucleotidyl transfer likely stabilizes the transition state and facilitates product release. In the one-metal-ion dependent $\mathrm{HUH}$ nucleases and topoisomerases a conserved Lys or Arg also occupies the position equivalent to R61 in hPol $\eta^{50}$. The involvement of an additional transient metal ion may be a general feature of both one- and two-metal-ion mechanism. 


\section{Methods}

hPol $\eta$, DNA and dATP complexes mixed with $\mathrm{Ca}^{2+}$ at 1:1 molar ratio were concentrated to $\sim 3 \mathrm{mg} / \mathrm{ml} \mathrm{hPol} \eta$ and crystallized by the hanging-drop vapor diffusion method ${ }^{29}$. For in crystallo reactions, crystals were first stabilized in 0.1 M MES (pH 6.8-7.2), $5 \mu \mathrm{M}$ dATP, $20 \%(\mathrm{w} / \mathrm{v}$ ) PEG 2K-MME and $1 \mathrm{mM}$ DTT at a specific $\mathrm{pH}$ for $\sim 30 \mathrm{~min}$, transferred in a nylon loop to the reaction buffer containing 0.1 M MES (pH 6.8-7.2), $1 \mathrm{mM} \mathrm{MgCl} 2,20 \%$ (w/v) PEG 2K-MME and $1 \mathrm{mM}$ DTT for the desired amount of time, followed by a quick dipping in a cryo-solution supplemented with $20 \%$ (w/v) glycerol and flash cooled in liquid nitrogen. The time courses were determined based on the Fo-Fc maps with all data scaled against and compared to the refined GS structures. The intermediate states were refined as a mixture of RS and PS, and their ratio at each time point was determined according to the reaction course (Fig. $2 b$ ) and difference (Fo-Fc) electron density maps. Catalytic rates $\left(k_{\text {obs }}\right)$, $k_{\text {cat }}$ and $K_{\mathrm{M}}$ were measured using the template/primer listed in Supplementary Table 3.

\section{Online Only Methods}

\section{Protein and Crystal Preparation}

hPol $\eta$ mutant S113A was made using QuikChange (Stratagene). Wildtype hPol $\eta$ (residues 1-432) and S113A mutant proteins were expressed and purified as described ${ }^{29}$. The ternary complexes of hPol $\eta$, DNA and dATP were mixed with $\mathrm{Ca}^{2+}$ at 1:1 molar ratio and concentrated to a protein concentration of $\sim 3 \mathrm{mg} / \mathrm{ml}$. Oligonucleotides used for original (A:T pair at the DNA end) and three "loosely packed" crystals (T:G or G:T mispaired and an unpaired A) are shown in Supplementary Table 2. An unpaired nucleotide at the primer 5' end was disordered in the original $\mathrm{hPol} \eta$ structures ${ }^{35}$, and was therefore removed to improve the diffraction quality. All crystals were obtained using the hanging-drop vapor diffusion method against a reservoir solution containing 0.1 M MES (pH 6.0) and 9-17\% (w/v) PEG 2K-MME and streak seeding.

\section{Chemical Reaction in crystallo}

Based on diffraction qualities, the complexes containing the original A:T and T:G-end DNA were selected for chemical reaction in crystallo. These crystals were first transferred and incubated in a pre-reaction buffer containing 0.1 M MES (pH 6.8-7.2), $5 \mu \mathrm{M} \mathrm{dATP}, 20 \%$ (w/v) PEG 2K-MME and $1 \mathrm{mM}$ DTT for $\sim 30 \mathrm{~min}$. For the $\mathrm{pH} 6.8$ time course (Fig. 2b, Table S1b) and translocation in the TG crystal, the pre-reaction buffer also contained $5 \mu \mathrm{M}$ $\mathrm{MgCl}_{2}$. The different pre-reaction buffer might cause the larger variations of the $\mathrm{pH} 6.8$ reactions. Chemical reaction was initiated by transferring the crystals with a Nylon loop into a reaction buffer containing 0.1 M MES (pH 6.8-7.2), $1 \mathrm{mM} \mathrm{MgCl}_{2}, 20 \%$ (w/v) PEG 2KMME and $1 \mathrm{mM}$ DTT. After incubation for a desired time point (40s and intervals of $\sim 40 \mathrm{~s}$ ), the crystals were quickly dipped in a cryo-solution supplemented with $20 \%(\mathrm{w} / \mathrm{v})$ glycerol and flash cooled in liquid nitrogen. For in crystallo reactions, MES buffer was titrated by $\mathrm{KOH}$ and not $\mathrm{NaOH}$ to avoid binding of $\mathrm{Na}^{+}$ion at the A site. To observe product release, TG crystals were soaked in $5 \mu \mathrm{M}$ dATP and $5 \mu \mathrm{M} \mathrm{MgCl}_{2}$ for 30 min and chased with addition of $1 \mathrm{mM} \mathrm{MgCl} 2$ for $1-8 \mathrm{~min}$. 


\section{Data Collection and Structure Determination}

Diffraction data were collected at $100 \mathrm{~K}$ on beamlines 22ID and 22BM of the Advanced Photon Source. Data were processed with HKL2000 ${ }^{51}$ or XDS ${ }^{52}$, and converted to structure factors by TRUNCATE. All data were isomorphic in the $P 6_{1}$ space group and processed with identical unit-cell parameters $a=b=98.8 \AA$ and $c=82.4 \AA$ for structure and electron density comparison. All structural figures were drawn using PyMOL (http:// www.pymol.org).

To monitor the new bond formation (Fig. 2a), Fo-Fc maps are calculated using the Fo of 40s, 80s, 140s and 230s after addition of $1 \mathrm{mM} \mathrm{Mg}^{2+}(\mathrm{pH} 7.0)$ and the $\mathrm{Fc}$ of the refined RS structure (40s) with the $3^{\prime}-\mathrm{OH}$ of the primer end, the A site $\mathrm{Mg}^{2+}$ and the a-phosphate of dATP omitted. To determine the reaction time courses (Fig. 2b and Supplementary Fig. 1-3), all data were scaled against and compared to the refined GS structure, and electron densities for the new bond (between the $3^{\prime}-\mathrm{OH}$ of the primer strand and the a-phosphorus of dATP) and the metal ions were measured in the Fo-Fc map (with the B-site metal ion omitted) at each time point using programs in $\mathrm{CCP} 4{ }^{53}$. After refinement of the GS structure, the intermediate structures were refined as a mixture of RS and PS using PHENIX ${ }^{54}$ and COOT ${ }^{55}$. The ratio of RS and PS at each time point was determined according to the time course of the new bond formation (Fig. 2b) and difference (Fo-Fc) electron density maps. For high-resolution refinement $(\sim 1.5 \AA$ resolution), the translation-libration-screw refinement was applied. Data collection and refinement statistics are summarized in Supplementary Table 1.

\section{Kinetic Measurements}

Kinetic measurements including $K_{\mathrm{m}}$ and $k_{\text {cat }}$ were done using the template/primer shown in supplementary Table 3. The basic reaction mixture contained $2.5 \mathrm{nM}$ hPol $\eta, 5 \mathrm{uM} 5^{\prime}$-FAMlabeled primer and template, and $0-80 \mu \mathrm{M} \mathrm{dNTP}$ in $40 \mathrm{mM}$ Tris- $\mathrm{HCl}(\mathrm{pH} 7.5), 5 \mathrm{mM}$ $\mathrm{MgCl}_{2}, 10 \mathrm{mM}$ dithiothreitol, $100 \mathrm{mM} \mathrm{KCl}, 0.1 \mathrm{mg} / \mathrm{ml}$ bovine serum albumin, and $5 \%$ glycerol. For the metal ion competition assay, $\mathrm{Mg}^{2+}$ was increased from 0 to $1.0 \mathrm{mM}$ at 0.1 $\mathrm{mM}$ step and $\mathrm{Ca}^{2+}$ was decreased to keep the combined concentration of $1.0 \mathrm{mM}$. The effects of $\mathrm{pH}$ were screened from $\mathrm{pH} 6.0$ to $\mathrm{pH}$ 8.0. All reactions took place at room temperature for 4 or 8 min and were stopped by addition of 10X formamide loading buffer to the final concentrations of $8 \%$ formamide, $1 \mathrm{mM} \mathrm{EDTA} \mathrm{(pH} \mathrm{8.0)} \mathrm{and} 0.1 \mathrm{mg} / \mathrm{ml}$ xylene cyanol. After heating to $90{ }^{\circ} \mathrm{C}$ for $3 \mathrm{~min}$ and immediately placing on ice, products were resolved on $20 \%$ poly-acrylamide sequencing gels containing 5.5 M urea. Quantification and curve fitting were carried out as described ${ }^{20} . K_{\mathrm{M}}, k_{\mathrm{cat}}$ and $\left(k_{\mathrm{cat}} / K_{\mathrm{M}}\right)$ of WT and S113A hPol $\eta$ catalyzing single nucleotide incorporation using deoxyribonucleotide versus ribonucleotide primer are summarized in Supplementary Table 3 and plotted in Fig. $3 \mathrm{~b}$.

\section{Supplementary Material}

Refer to Web version on PubMed Central for supplementary material. 


\section{Acknowledgments}

We thank D. Leahy, M. Gellert and R. Craigie for editing the manuscript. The research was supported by the intramural research program of NIDDK, NIH (W.Y., T.N. and Y.Z.), the JSPS Institutional Program for Young Researcher Overseas Kumamoto University, and KUMAYAKU Alumni Research Fund (T.N.), Chinese Ministry of Education scholarship (Y.Z.), National Natural Science Foundation of China (Y.H.), and Grant-in-Aid for Scientific Research from the Ministry of Education, Culture, Sports, Science, and Technology of Japan (Y.Y.).

\section{References}

1. Echols H, Goodman MF. Fidelity mechanisms in DNA replication. Annu Rev Biochem. 1991; 60:477-511. [PubMed: 1883202]

2. Rothwell PJ, Waksman G. Structure and mechanism of DNA polymerases. Adv Protein Chem. 2005; 71:401-440. [PubMed: 16230118]

3. Brody RS, Frey PA. Unambiguous determination of the stereochemistry of nucleotidyl transfer catalyzed by DNA polymerase I from Escherichia coli. Biochemistry. 1981; 20:1245-1252. [PubMed: 7013792]

4. Steitz TA, Steitz JA. A general two-metal-ion mechanism for catalytic RNA. Proc Natl Acad Sci U S A. 1993; 90:6498-6502. [PubMed: 8341661]

5. Yang W, Lee JY, Nowotny M. Making and breaking nucleic acids: two-Mg2+-ion catalysis and substrate specificity. Mol Cell. 2006; 22:5-13. [PubMed: 16600865]

6. Johnson KA. Role of induced fit in enzyme specificity: a molecular forward/reverse switch. J Biol Chem. 2008; 283:26297-26301. [PubMed: 18544537]

7. Warshel A, et al. Electrostatic basis for enzyme catalysis. Chem Rev. 2006; 106:3210-3235. [PubMed: 16895325]

8. Pelletier H, Sawaya MR, Kumar A, Wilson SH, Kraut J. Structures of ternary complexes of rat DNA polymerase beta, a DNA template-primer, and ddCTP. Science. 1994; 264:1891-1903. [PubMed: 7516580]

9. Doublie S, Tabor S, Long AM, Richardson CC, Ellenberger T. Crystal structure of a bacteriophage T7 DNA replication complex at 2.2 A resolution. Nature. 1998; 391:251-258. [PubMed: 9440688]

10. Huang H, Chopra R, Verdine GL, Harrison SC. Structure of a covalently trapped catalytic complex of HIV-1 reverse transcriptase: implications for drug resistance. Science. 1998; 282:1669-1675. [PubMed: 9831551]

11. Li Y, Korolev S, Waksman G. Crystal structures of open and closedforms of binary and ternary complexes of the large fragment of Thermus aquaticus DNA polymerase I: structural basis for nucleotide incorporation. EMBO J. 1998; 17:7514-7525. [PubMed: 9857206]

12. Franklin MC, Wang J, Steitz TA. Structure of the replicating complex of a pol alpha family DNA polymerase. Cell. 2001; 105:657-667. [PubMed: 11389835]

13. Ling H, Boudsocq F, Woodgate R, Yang W. Crystal structure of a Y-family DNA polymerase in action: a mechanism for error-prone and lesion-bypass replication. Cell. 2001; 107:91-102. [PubMed: 11595188]

14. Berman AJ, et al. Structures of phi29 DNA polymerase complexed with substrate: the mechanism of translocation in B-family polymerases. EMBO J. 2007; 26:3494-3505. [PubMed: 17611604]

15. Johnson SJ, Taylor JS, Beese LS. Processive DNA synthesis observed in a polymerase crystal suggests a mechanism for the prevention of frameshift mutations. Proc Natl Acad Sci U S A. 2003; 100:3895-3900. [PubMed: 12649320]

16. Evans RJ, et al. Structure of PolC reveals unique DNA binding and fidelity determinants. Proc Natl Acad Sci U S A. 2008; 105:20695-20700. [PubMed: 19106298]

17. Wang F, Yang W. Structural insight into translesion synthesis by DNA Pol II. Cell. 2009; 139:1279-1289. [PubMed: 20064374]

18. Batra VK, et al. Magnesium-induced assembly of a complete DNA polymerase catalytic complex. Structure. 2006; 14:757-766. [PubMed: 16615916] 
19. Patel SS, Wong I, Johnson KA. Pre-steady-state kinetic analysis of processive DNA replication including complete characterization of an exonuclease-deficient mutant. Biochemistry. 1991; 30:511-525. [PubMed: 1846298]

20. Joyce CM, Benkovic SJ. DNA polymerase fidelity: kinetics, structure, and checkpoints. Biochemistry. 2004; 43:14317-14324. [PubMed: 15533035]

21. Showalter AK, Tsai MD. A reexamination of the nucleotide incorporation fidelity of DNA polymerases. Biochemistry. 2002; 41:10571-10576. [PubMed: 12186540]

22. Shah AM, Li SX, Anderson KS, Sweasy JB. Y265H mutator mutant of DNA polymerase beta. Proper teometric alignment is critical for fidelity. J Biol Chem. 2001; 276:10824-10831. [PubMed: 11154692]

23. Fiala KA, Suo Z. Mechanism of DNA polymerization catalyzed by Sulfolobus solfataricus P2 DNA polymerase IV. Biochemistry. 2004; 43:2116-2125. [PubMed: 14967051]

24. Cramer J, Restle T. Pre-steady-state kinetic characterization of the DinB homologue DNA polymerase of Sulfolobus solfataricus. J Biol Chem. 2005; 280:40552-40558. [PubMed: 16223720]

25. Choi JY, Guengerich FP. Adduct size limits efficient and error-free bypass across bulky N2guanine DNA lesions by human DNA polymerase eta. J Mol Biol. 2005; 352:72-90. [PubMed: 16061253]

26. Rothwell PJ, Mitaksov V, Waksman G. Motions of the fingers subdomain of klentaq1 are fast and not rate limiting: implications for the molecular basis of fidelity in DNA polymerases. Mol Cell. 2005; 19:345-355. [PubMed: 16061181]

27. Zhang H, Cao W, Zakharova E, Konigsberg W, De La Cruz EM. Fluorescence of 2-aminopurine reveals rapid conformational changes in the RB69 DNA polymerase-primer/template complexes upon binding and incorporation of matched deoxynucleoside triphosphates. Nucleic Acids Res. 2007; 35:6052-6062. [PubMed: 17766250]

28. Yang W, Woodgate R. What a difference a decade makes: insights into translesion DNA synthesis. Proc Natl Acad Sci U S A. 2007; 104:15591-15598. [PubMed: 17898175]

29. Biertumpfel C, et al. Structure and mechanism of human DNA polymerase eta. Nature. 2010; 465:1044-1048. [PubMed: 20577208]

30. Zhao Y, et al. Structural basis of human DNA polymerase eta-mediated chemoresistance to cisplatin. Proc Natl Acad Sci U S A. 2012 in press.

31. Castro C, et al. Two proton transfers in the transition state for nucleotidyl transfer catalyzed by RNA- and DNA-dependent RNA and DNA polymerases. Proc Natl Acad Sci U S A. 2007; 104:4267-4272. [PubMed: 17360513]

32. Garcia-Diaz M, Bebenek K, Krahn JM, Pedersen LC, Kunkel TA. Role of the catalytic metal during polymerization by DNA polymerase lambda. DNA Repair (Amst). 2007; 6:1333-1340. [PubMed: 17475573]

33. Le Du MH, et al. Artificial evolution of an enzyme active site: structural studies of three highly active mutants of Escherichia coli alkaline phosphatase. J Mol Biol. 2002; 316:941-953. [PubMed: 11884134]

34. Graham DL, et al. $\mathrm{MgF}(3)(-)$ as a transition state analog of phosphoryl transfer. Chem Biol. 2002; 9:375-381. [PubMed: 11927263]

35. Lee JY, Yang W. UvrD helicase unwinds DNA one base pair at a time by a two-part power stroke. Cell. 2006; 127:1349-1360. [PubMed: 17190599]

36. Cavanaugh NA, Beard WA, Wilson SH. DNA polymerase beta ribonucleotide discrimination: insertion, misinsertion, extension, and coding. J Biol Chem. 2010; 285:24457-24465. [PubMed: 20519499]

37. Wang L, Broyde S, Zhang Y. Polymerase-tailored variations in the water-mediated and substrateassisted mechanism for nucleotidyl transfer: insights from a study of T7 DNA polymerase. J Mol Biol. 2009; 389:787-796. [PubMed: 19389406]

38. Wang L, Yu X, Hu P, Broyde S, Zhang Y. A water-mediated and substrate-assisted catalytic mechanism for Sulfolobus solfataricus DNA polymerase IV. J Am Chem Soc. 2007; 129:47314737. [PubMed: 17375926] 
39. Polesky AH, Dahlberg ME, Benkovic SJ, Grindley ND, Joyce CM. Side chains involved in catalysis of the polymerase reaction of DNA polymerase I from Escherichia coli. J Biol Chem. 1992; 267:8417-8428. [PubMed: 1569092]

40. Copeland WC, Wang TS. Mutational analysis of the human DNA polymerase alpha. The most conserved region in alpha-like DNA polymerases is involved in metal-specific catalysis. J Biol Chem. 1993; 268:11028-11040. [PubMed: 8496164]

41. Zakharova E, Wang J, Konigsberg W. The activity of selected RB69 DNA polymerase mutants can be restored by manganese ions: the existence of alternative metal ion ligands used during the polymerization cycle. Biochemistry. 2004; 43:6587-6595. [PubMed: 15157091]

42. Kim EE, Wyckoff HW. Reaction mechanism of alkaline phosphatase based on crystal structures. Two-metal ion catalysis. J Mol Biol. 1991; 218:449-464. [PubMed: 2010919]

43. Romier C, Dominguez R, Lahm A, Dahl O, Suck D. Recognition of single-stranded DNA by nuclease P1: high resolution crystal structures of complexes with substrate analogs. Proteins. 1998; 32:414-424. [PubMed: 9726413]

44. Garcin ED, et al. DNA apurinic-apyrimidinic site binding and excision by endonuclease IV. Nat Struct Mol Biol. 2008; 15:515-522. [PubMed: 18408731]

45. Shan S, Yoshida A, Sun S, Piccirilli JA, Herschlag D. Three metal ions at the active site of the Tetrahymena group I ribozyme. Proc Natl Acad Sci U S A. 1999; 96:12299-12304. [PubMed: 10535916]

46. Stahley MR, Strobel SA. Structural evidence for a two-metal-ion mechanism of group I intron splicing. Science. 2005; 309:1587-1590. [PubMed: 16141079]

47. Ding X, Rasmussen BF, Petsko GA, Ringe D. Direct structural observation of an acyl-enzyme intermediate in the hydrolysis of an ester substrate by elastase. Biochemistry. 1994; 33:92859293. [PubMed: 8049229]

48. Scott WG, Murray JB, Arnold JR, Stoddard BL, Klug A. Capturing the structure of a catalytic RNA intermediate: the hammerhead ribozyme. Science. 1996; 274:2065-2069. [PubMed: 8953035]

49. Murray JB, Szoke H, Szoke A, Scott WG. Capture and visualization of a catalytic RNA enzymeproduct complex using crystal lattice trapping and X-ray holographic reconstruction. Mol Cell. 2000; 5:279-287. [PubMed: 10882069]

50. Yang W. Nucleases: diversity of structure, function and mechanism. Q Rev Biophys. 2011; 44:193. [PubMed: 20854710]

51. Otwinowski Z, Minor W. Processing of X-ray diffraction data collected in oscillation mode. Methods Enzymol. 1997; 276:307-326.

52. Kabsch W. XDS. Acta Crystallographica Section D. 2010; 66:125-132.

53. CCP4. The CCP4 suite: programs for protein crystallography. Acta Crystallogr D. 1994; 50:760763. [PubMed: 15299374]

54. Adams PD, et al. PHENIX: a comprehensive Python-based system for macromolecular structure solution. Acta Crystallogr D Biol Crystallogr. 2010; 66:213-221. [PubMed: 20124702]

55. Emsley P, Lohkamp B, Scott WG, Cowtan K. Features and development of Coot. Acta Crystallogr D Biol Crystallogr. 2010; 66:486-501. [PubMed: 20383002] 
a
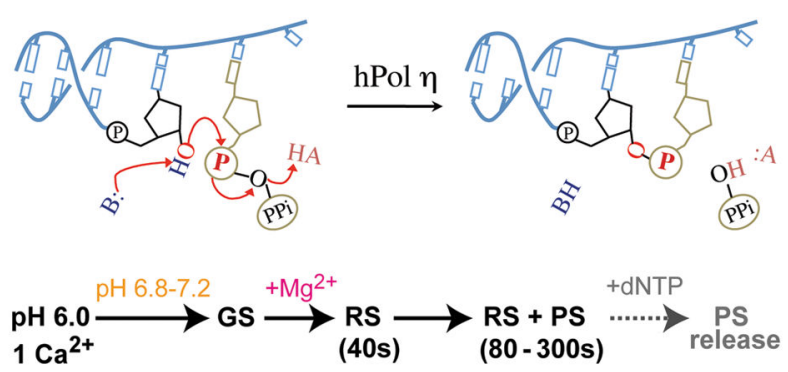

b

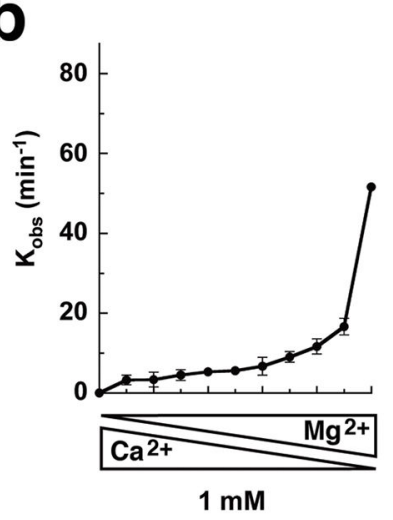

C

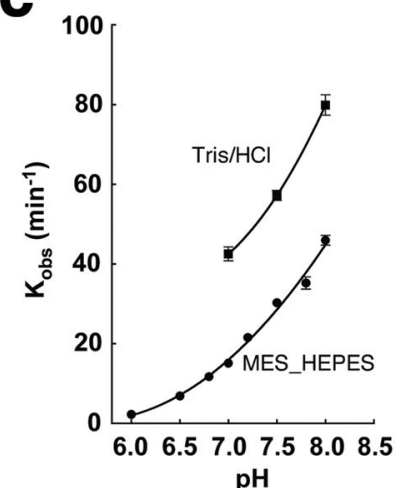

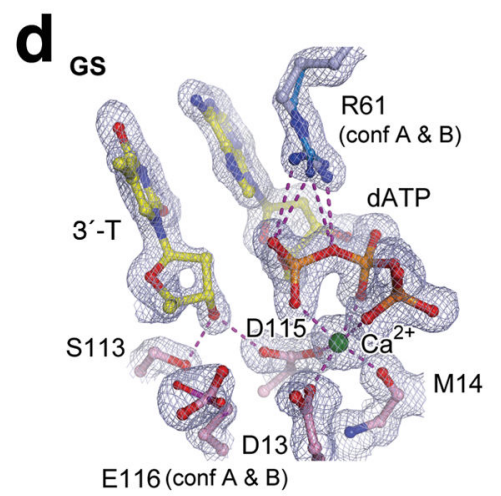

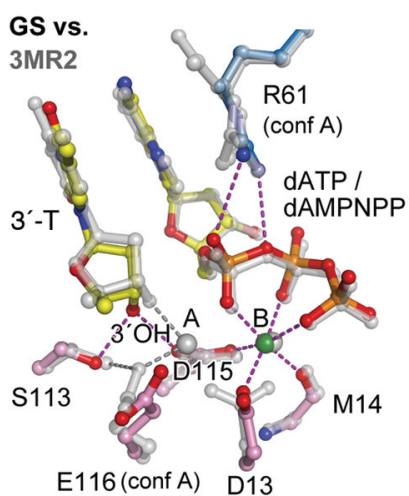

Fig 1.

$\mathrm{pH}$ and metal ion dependence of hPol $\eta$. (a) Diagrams of DNA synthesis and the procedure of the in crystallo reaction. AH and B stands for general acid and base, respectively. (b) Reaction rate $\left(\mathrm{k}_{\mathrm{obs}}\right)$ is plotted against mixed $\mathrm{Mg}^{2+}$ and $\mathrm{Ca}^{2+}$ at the total of $1 \mathrm{mM}$. (c) The $\mathrm{pH}$ and buffer dependent reaction rates. (d) The GS structure. The active site is superimposed with the $2 \mathrm{Fo}-\mathrm{Fc}$ electron density contoured at $1.2 \sigma$ (upper panel) or with the non-reactive dAMPNPP ternary complex (PDB: 3MR2, silver, lower panel). Hydrogen bonds and metal ion coordination are shown as dashed lines. 

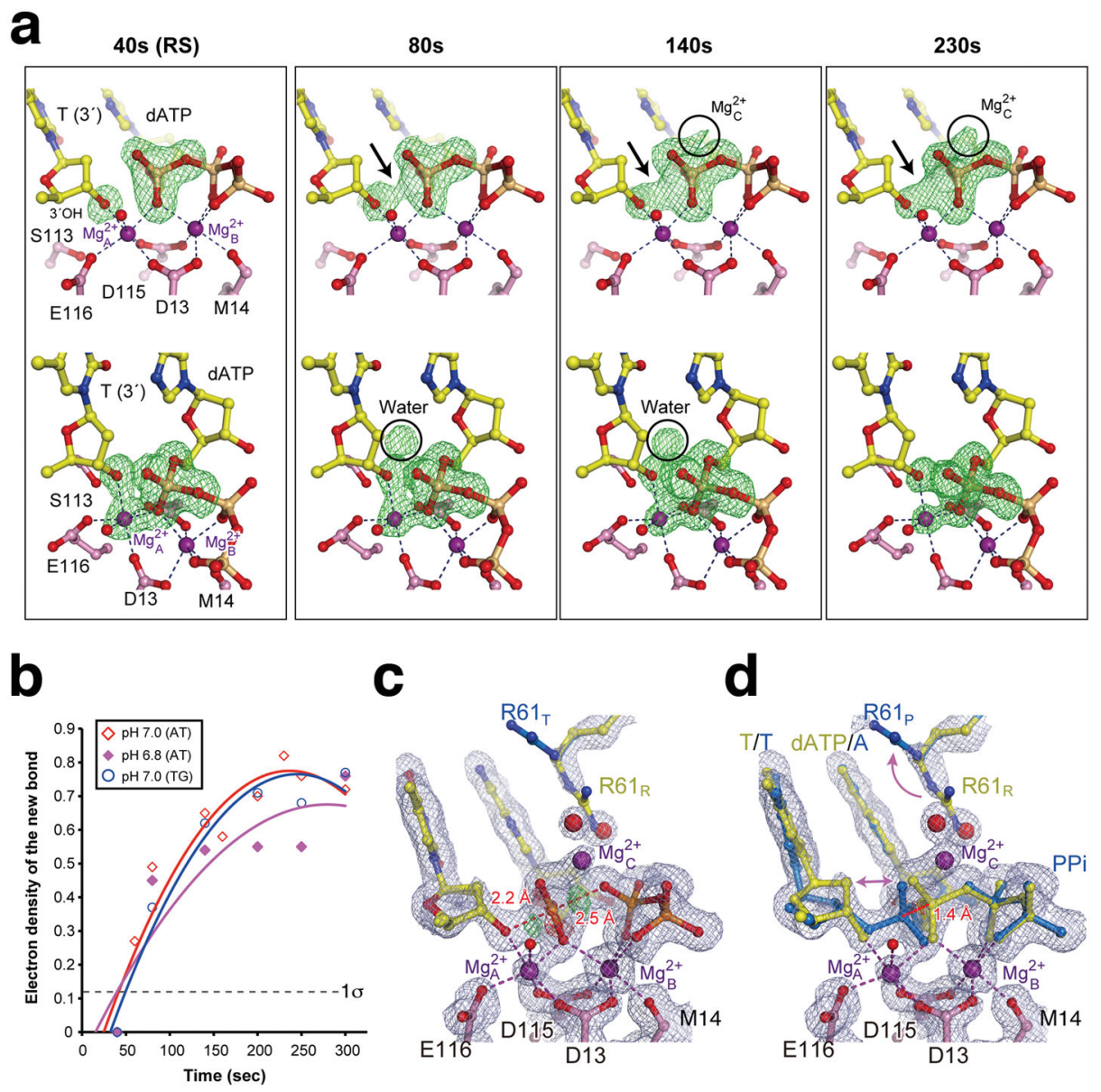

Fig. 2.

Reaction time course. (a) Two views (upper and lower panels) of omit $\mathrm{Fo}_{40-230 \mathrm{~s}}-\mathrm{Fc}_{40 \mathrm{~s}}$ maps (4.0б) superimposed onto the 40s structure ( $\mathrm{pH} 7.0)$. The emerging densities are pointed out or circled. (b) A plot of the absolute peak height of the new bond density versus reaction time at pH 6.8 and 7.0 in AT and TG crystals (Supplementary Table 1a,b). The noise level $(1 \sigma)$ is indicated. (c) The $230 \mathrm{~s}$ structure refined as the pentacovalent transition

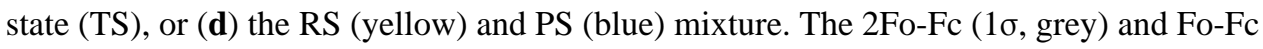
map $( \pm 3.0 \sigma$ green and red) are superimposed. 

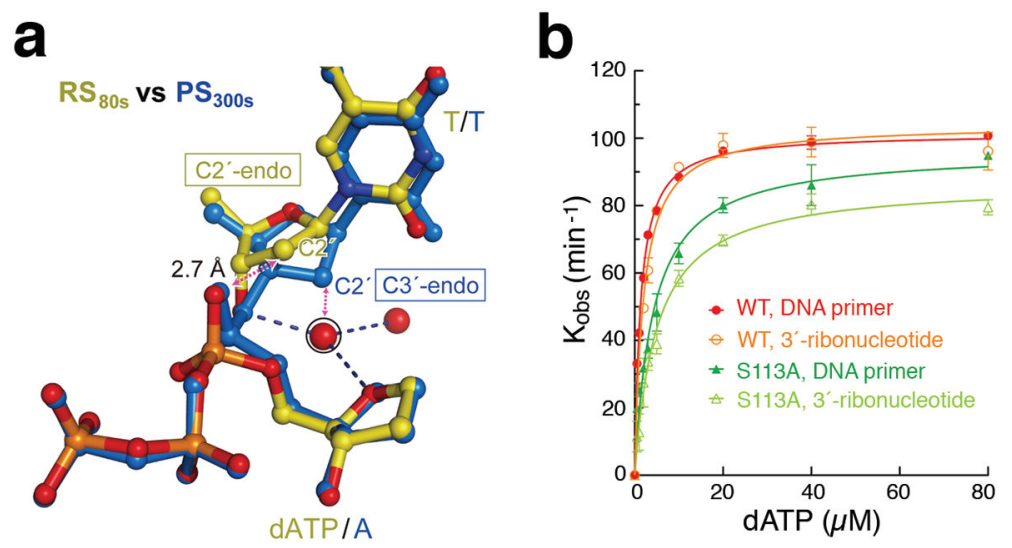

Fig. 3.

Deprotonation of the $3^{\prime}-\mathrm{OH}$. (a) Superposition of the refined RS (80s, yellow) and PS (300s, blue). The transient water molecule, likely deprotonating the $3^{\prime}-\mathrm{OH}$, is circled. The sugar pucker at the primer $3^{\prime}$-end changes from $\mathrm{C} 2^{\prime}$-endo in the RS to $\mathrm{C} 3^{\prime}$-endo in the PS. The clashes between the a-phosphate and the $\mathrm{C} 2^{\prime}$ if it is $\mathrm{C} 2^{\prime}$-endo, and between the $\mathrm{C} 2^{\prime}$ and the transient water if the water doesn't depart, are indicated by dashed double arrowheads. (b) WT and S113A mutant hPol $\eta$ can both extend primer with a ribonucleotide at the $3^{\prime}$ end (lighter color) as with pure DNA (darker color). 

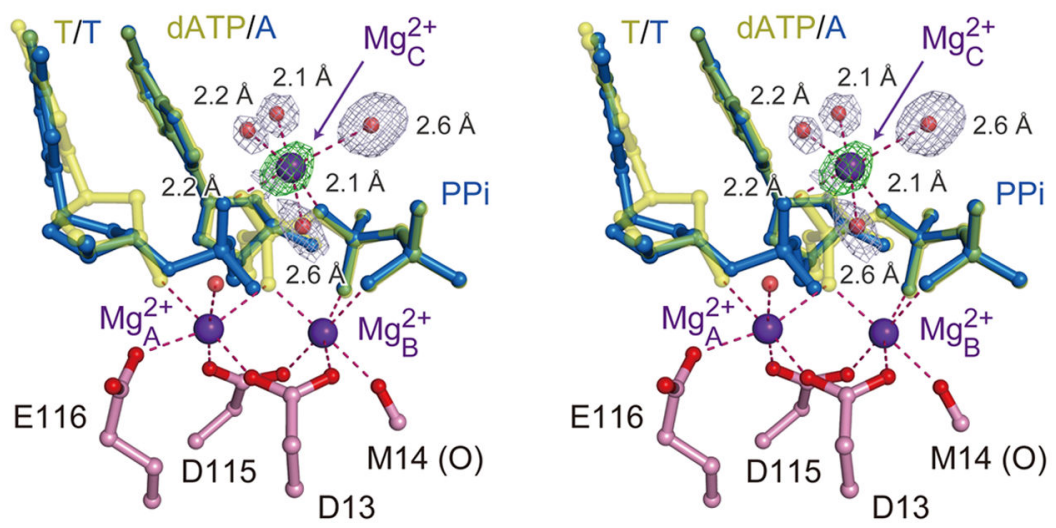

Fig. 4.

The $3^{\text {rd }} \mathrm{Mg}^{2+}$ ion in hPol $\eta$ catalysis. A stereo view of the three metal ions observed in the intermediate state of $230 \mathrm{~s}$ after $\mathrm{Mg}^{2+}$ addition, which consists of a mixture of PS (blue) and RS (yellow). The $3^{\text {rd }} \mathrm{Mg}^{2+}$ has six ligands, four of which are water molecules. The $2 \mathrm{Fo}-\mathrm{Fc}$ map contoured at $1.5 \sigma$ (grey) and Fo-Fc map with the $3^{\text {rd }} \mathrm{Mg}^{2+}$ omitted contoured at $4.0 \sigma$ (green) are overlaid with the ball-and-stick model. 


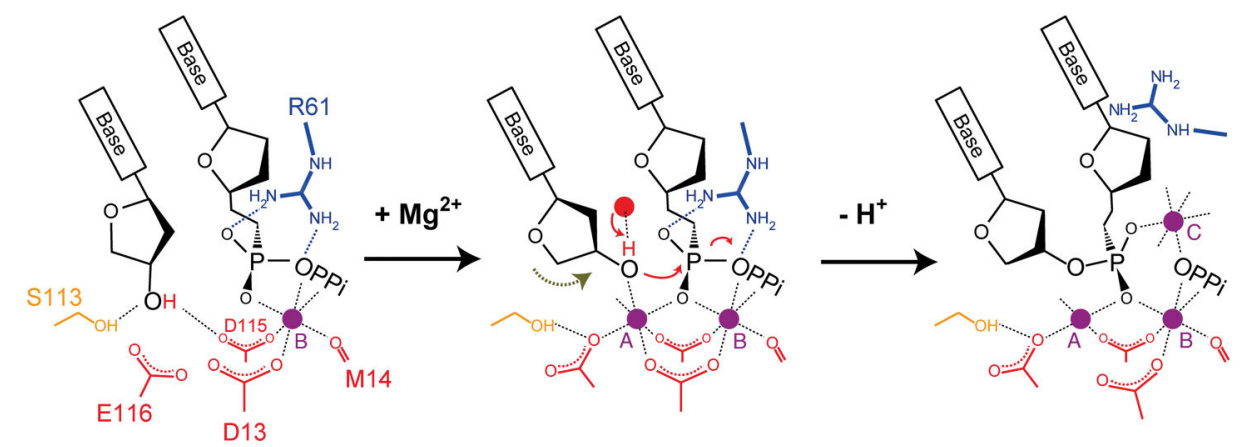

Fig. 5.

A proposed mechanism for metal-ion dependent polymerase reaction. The B-site metal ion is stably associated with the incoming dNTP and the enzyme. Binding of $\mathrm{Mg}^{2+}$ at the A-site aligns the reactants, in particular the $3^{\prime}-\mathrm{OH}$, and promotes its deprotonation, which is assisted by the dNTP and the transient water. After the reaction is initiated and before the products are released, a third metal ion replaces R61 to stabilize the reaction intermediates. 